\title{
Implementing Augmented Reality in Learning
}

\author{
Ajit Singh \\ Patna Women's College, Bihar, India
}

\begin{abstract}
Technologies are changing and ever growing. One of the newest developing technologies is augmented reality (AR), which can be applied to many different existing technologies, such as computers, tablets, and smartphones. AR technology can also be utilized through wearable components, for example, glasses. Throughout this paper review on $\mathrm{AR}$, the following aspects are discussed at length: research explored, theoretical foundations, applications in education, challenges, reactions, and implications. Several different types of AR devices and applications are discussed at length, and an in-depth analysis is done on several studies that have implemented AR technology in an educational setting.
\end{abstract}

Keywords: augmented reality, learning and development, educator, flow theory, just-in-time learning

\section{Introduction}

In today's world, technology has become a crucial part of our lives. It has changed how people think and apply knowledge. One of the newest developing technologies is augmented reality (AR), which can be applied to computers, tablets, and smartphones. AR affords the ability to overlay images, text, video, and audio components onto existing images or space. AR technology has gained a following in the educational market for its ability to bridge gaps and bring a more tangible approach to learning. Learner-centered activities are enhanced by the incorporation of virtual and real-world experience. AR has the potential to change education to become more efficient in the same way that computers and Internet have.

\section{Research}

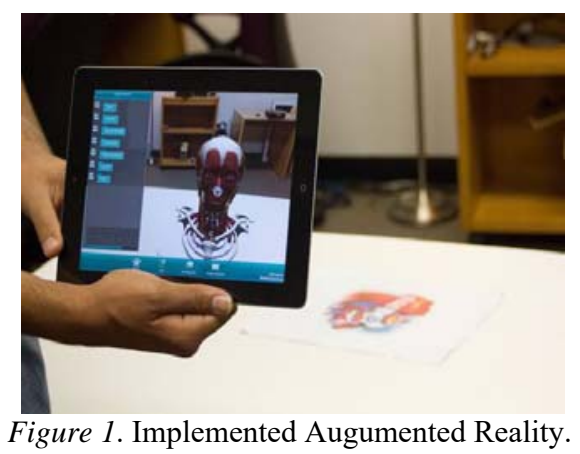

Research conducted for this literature review focused on learning applications of AR. The initial search of K-12 applications was far too broad to provide a valuable synthesis. The keywords included learning applications, science or Science, Technology, Engineering, and Math (STEM) focus, and augmented reality.

Ajit Singh, M. Phil. in Computer Science, Assistant Professor, Patna Women's College, Bihar, India. 
Journals with a concentration in technology and education that held significance to AR within the classroom setting were sought. References were included that explained the concept of AR as well as studies that implemented AR. Most of the references for this analysis were published within the past five years; however, a few articles included were published as early as 2010 .

\section{Theoretical Foundations}

AR educational programs are learner-centered and related to learner interests. It allows learners to explore the world in an interactive way. Constructivism also encourages learners to work collaboratively, and AR provides learners the opportunity to do this in a traditional school setting as well as in distance education. Dunleavy, Dede, and Mitchell (2009) believed that the engagement of the learner as well as their identity as a learner is formed by participating in collaborative groups and communities. Constructivism has also changed the role of the educator to become a facilitator, where the responsibility to organize, synthesize, and analyze content information is in the hands of the learner (DeLucia, Francese, Passero, \& Tortoza, 2012).

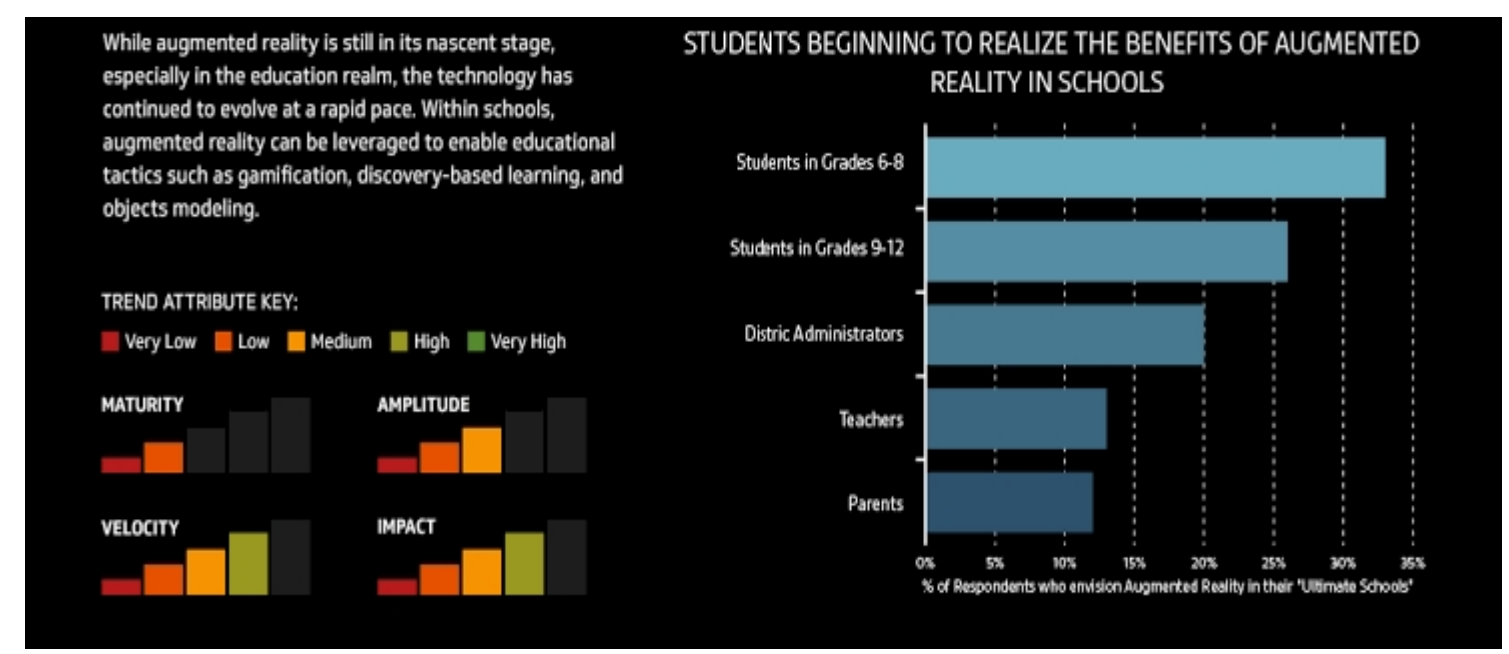

Figure 2. Benefits Analysis of Augamented Reality for the school and learners.

Flow theory describes how people who are engaged in meaningful activities are more likely to stay focused. Bressler and Bodzin (2013) investigated a science gaming experience in relation to flow experience. Their study had a mean flow experience score of $82.4 \%$, which indicates that the average learner experienced flow throughout the science mystery game that they played on a smartphone. This particular type of AR, as well as various others, connects their real-world surroundings to learning in a new and engaging way.

\section{Implementing $A R$ in Learning}

AR allows flexibility in use that is attractive to education. AR technology can be utilized through a variety of mediums including desktops, mobile devices, and smartphones. The technology is portable and adaptable to a variety of scenarios. AR can be used to enhance content and instruction within the traditional classroom, supplement instruction in the special education classroom, extend content into the world outside the classroom, and be combined with other technologies to enrich their individual applications.

\section{Traditional Classroom Uses}

In any educational setting, there are often limitations in the various resources available. This is often seen 
foremost in the traditional classroom. Due to budget restraints or constraints on time, the means to teach learners in scenarios that allow them to learn by doing can be a challenge. Desktop AR allows learners to combine both real and computer-generated images. Iordache and Pribeanu (2009) used desktop AR that combined a screen, glasses, headphones, and a pointing device that allowed learners to conduct a hands-on exploration of a real object, in this case a flat torso, with superimposed virtual images. Computer images could show the process, but the pointing device allowed learners to guide their learning.

Classrooms can shift from the traditional lecture style setting to one that is more lab- and learner- oriented. A case study conducted with a visual arts class noted that allowing learners to freely explore a room that was set up with webcams and desktops encouraged more activity while the learners perceived that they were more motivated to learn (Serio, Ibanez, \& Carlos, 2013).

Instead of receiving information via images and lecture, learners had access to multimodal representations including text, audio, video, and 3D models.

\section{Special Learning Uses}

Because of the variety of tools that can be overlaid in an augmented environment, learners with physical disabilities can benefit from the potential learning aides that could be incorporated. Something as simple as overlaying audio for those with visual impairments or text for those with hearing disabilities can be effective tools when considering disability access (Forsyth, 2011). Head-mounted displays (HMD) can provide a hands-free device to project the overlay visuals to a learner and adjust the images based on the orientation of the learner while other devices enable learners to interact with the environment via voice recognition, gesture recognition, gaze tracking, and speech recognition. Bringing this technology to the classroom has the potential to allow for differentiated instruction and enrichment of the learning experience of learners with special needs. Evaluation trials conducted by Arvantis et al. (2009) showed that using wearable AR technology with learners who had physical disabilities produced, "interestingly comparable results with able-bodied users", (p. 250) in terms of "wearability" and pedagogy.

\section{Outside the Classroom}

Mobile applications can extend the traditional classroom beyond the physical walls. Annetta, Burton, Frazier, Cheng, and Chmiel (2012) reported that the percentage of 12 to 17 year olds who have their own mobile device is $75 \%$, compared to $45 \%$ in 2004 , and regardless of a learner's socioeconomic status, the number of learners carrying their own mobile devices is growing exponentially every year. Camera phones and smartphones allow users to gather information in a variety of locations. Quick Response (QR) codes and Global Positioning System (GPS) coordinates can be used to track and guide movement of the learners. Although several researchers chose to take learners off campus and conduct investigations in a field trip setting, others chose to remain within the grounds of the school.

An important point to note from this research is that GPS will not work inside of buildings. Therefore, any indoor activities would need to be conducted without a location-based AR technology.

\section{Challenges}

\section{Training}

Training is an important aspect of AR. "Most educational AR systems are single-use prototypes for specific projects, so it is difficult to generalize evaluation results" (Billinghurst \& Dunser, 2012, p. 61). 
Educators did not feel confident when setting up or implementing the program. In addition, educators who are normally lecture focused had a hard time letting go and allowing learners to explore the learning environment on their own.

A training should be provided for educators to learn a hands-off approach with their learners and show them how this way of teaching will foster an effective learning environment. The fear of not knowing what is on each learner's device can be elevated according to the authors through the process of allowing the learners more control over their learning.

\section{Technical Problems}

Dunleavy et al. (2009) showed that the GPS failed 15-30\% during the study. A GPS error refers to either the software of the GPS itself or incorrect setup. This was considered the "most significant" malfunction. Other malfunctions identified in this study were the ability for the devices to be effectively used outdoors. The glare from the sun as well as the noisy environment could impair the learning of the learners.

There are several different kinds of devices that can be used when implementing AR in the classroom. Glasses, hand-held devices, and headwear are ways for the user to see computer-generated images imprinted on their reality.

Acquiring devices that are calibration free or auto-calibrated can be beneficial to the user as to avoid malfunction and user frustration.

\section{Learner Issues}

One issue identified in Dunleavy et al. (2009) determined that some AR situations can be dangerous. In this particular Alien Contact! scenario, learners must look at their handheld devices to participate. When engaging in activities outdoors, the learners are unable to work on their devices and watch where they are going simultaneously. Therefore, learners were found to be wandering into roadways and needed to be redirected to safety by educators.

\section{Reactions}

\section{Learners}

Overall, learners reacted positively to using AR technology both in and outside of the classroom.

Learners also reported that learning in an AR environment is more stimulating and appealing than viewing a traditional slide presentation (i.e., Microsoft PowerPoint and SmartNotebook) because they preferred the audio, video, and feeling as if they were part of the 3D model that was transposed into a real physical space (Serio et al., 2013).

\section{Educators}

Educators may feel alarmed as if AR will "overtake" their classrooms; it seems that once learners experience this type of learning, they will not go back to their previous ways of learning. However, Annetta et al. (2012) expressed that AR can be an activity to engage learners in future units and discussions. Billinghurst and Dunser (2012) believed that AR is a new form of face-to-face instruction, as learners share the learning experience. Educators have reported learners taking responsibility and ownership of their learning (Kamarainen et al., 2013). Therefore, educators using AR technology are becoming facilitators to their learners. 


\section{Implications for Research}

The importance of this literature review is that it not only showcases the current trends in AR technology but also its focus on the increased research and potential further application in the educational setting. Several components remain to be explored. When using AR outside of the classroom, educators and learners are able to use this as a tool for physical activity (Dunleavy et al., 2009). Linking learning with exercise and activity in an educational way can improve the perception that technology creates a non-interactive environment (National Association for the Education of Young Children [NAEYC] \& Fred Rogers Center, 2012).

Another is that the amount of visual information that can be displayed on the screen can be overwhelming to learners. Studies should further explore the effects AR has on cognitive load in the brain and how much information should be displayed before it turns from a beneficial device into a distracting device (Bressler \& Bodzin, 2013; Van Krevelen \& Poelman, 2010).

\section{Conclusion}

AR has already begun to help learners learn more efficiently as well as increase their knowledge retention (Billinghurst \& Dunser, 2012). However, before AR becomes mainstream in education, like desktops, laptops, tablets, and even cell phones have become, special consideration must be taken into account on the usability, cost, power usage, visual appearance and the like, in order for content AR simulations activities to become part of the regular academic curriculum (Van Krevelen \& Poelman, 2010). AR has proved to be an engaging way for learners to participate in their learning. This new technology allows the learning to be learner-centered and create opportunities for collaboration that fosters a deeper understanding of the content. AR is on the way to becoming an important part of education, and its use will continue to grow.

\section{References}

Annetta, L., Burton, E. P., Frazier, W., Cheng, R., \& Chmiel, M. (2012). Augmented reality games: Using technology on a budget. Science Scope, 36(3), 54-60.

Arvanitis, T. N., Petrou, A., Knight, J. F., Savas, S., Sotiriou, S., Gargalakos, M., \& Gialouri, E. (2009). Human factors and qualitative pedagogical evaluation of a mobile augmented reality system for science education used by learners with physical disabilities. Personal and Ubiquitous Computing, 13(3), 243-250.

Azuma, R., Baillot, Y., Behringer, R., Feiner, S., Julier, S., \& MacIntyre, B. (2001). Recent advances in augmented reality. Computer Graphics and Applications, IEEE , 21(6), 34-47.

Benford, S., Anastasi, R., Flintham, M., Greenhalgh, C., Tan-davanitj, N., Adams, M., \& Row-Farr, J. (2003). Coping with uncertainty in a location-based game. IEEE Pervasive Computing, 2(3), 34-41.

Billinghurst, M., \& Dunser, A. (2012). Augmented reality in the classroom. Computer, 45(7), 56-63.

Bressler, D. M., \& Bodzin, A. M. (2013). A mixed methods assessment of learners' flow experience during a mobile augmented reality science game. Journal of Computer Assisted Learning, 29(6), 505-517. doi: 10.1111/jal.12008

Collins, A., \& Halverston, R. (2009). Rethinking education in the age of technology: The digital revolution and schooling in America. New York: Educators College Press.

DeLucia, A., Francese, R., Passero, I., \& Tortoza, G. (2012). A collaborative augmented campus based on location-aware mobile technology. International Journal of Distance Education Technologies, 10(1), 55-71. Retrieved from http://dx.doi.org.ezproxy.liberty.edu:2048/10.4018/jdet.2012010104

DNews. (2013, February 20). Google glass and augmented reality's future. Retrieved from http://youtu.be/qdD5-woi_os

Dunleavy, M., Dede, C., \& Mitchell, R. (2009). Affordances and limitations of immersive participatory augmented reality simulations for teaching and learning. Journal of Science Education and Technology, 18(1), 7-22. 
Enyedy, N., Danish, J. A., Delacruz, G., \& Kumar, M. (2012). Learning physics through play in an augmented reality environment. International Journal of Computer-Supported Collaborative Learning, 7(3), 347-378. Retrieved from http://dx.doi.org/10.1007/s11412-012-9150-3

Forsyth, E. (2011). Ar u feeling appy? Augmented reality, apps and mobile access to local studies information. Australasian Public Libraries and Information Services, 24(3), 125.

Goodrich, R. (2013, May 29). What is augmented reality? Retrieved from http://www.livescience.com/34843-augmented-reality.html

Iordache, D. D., \& Pribeanu, C. (2009). A comparison of quantitative and qualitative data from a formative usability evaluation of an augmented reality learning scenario. Informatica Economica, 13(3), 67-74.

Kamarainen, A. M., Metcalf, S., Grotzer, T., Browne, A., Mazzuca, D., Tutwiler, M. S., \& Dede, C. (2013). EcoMOBILE: Integrating augmented reality and probeware with environmental education field trips. Computers \& Education, 68, 545-556. doi:10.1016/j.compedu.2013.02.018

Morrison, A., Mulloni, A., Lemmela, S., Oulasvirta, A., Jacucci, G., Peltonen, P., Schmalstieg, D., \& Regenbrecht, H. (2011). Collaborative use of mobile augmented reality with paper maps. Computers \& Graphics, 35(4), 789-799.

Mullen, T. (2011). Prototyping augmented reality. Indianapolis, IN: John Wiley \& Sons, Inc.

National Association for the Education of Young Children (NAEYC), \& Fred Rogers Center. (2012). Technology and interactive media as tools in early childhood programs serving children from birth through age 8 . Retrieved from http://www.naeyc.org/files/naeyc/file/positions/PS_technology_WEB2.pdf

Rigby, C. S., \& Przybylski, A. K. (2009). Virtual worlds and the learner hero: How today's video games can inform tomorrow's digital learning environments. Theory and Research in Education, 7(2), 214-223.

Serio, A. D., Ibanez, M. B., \& Carlos, D. K. (2013). Impact of an augmented reality system on learners' motivation for a visual art course. Computers \& Education, 68, 586-596. Retrieved from http://dx.doi. org/10.1016/j.compedu.2012.03.002

Van Krevelen, D. W. F., \& Poelman, R. (2010). A survey of augmented reality technologies, applications and limitations. The International Journal of Virtual Reality, 9(2), 1-20. Retrieved from http://kjcomps.6te.net/upload/paper1\%20.pdf

Wang, X. (2012). Augmented reality: A new way of augmented learning. ELearn, 10. doi:10.1145/2380716.2380717

Wither, J., Tsai, Y., \& Azuma, R. (2011). Indirect augmented reality. Computers \& Graphics, 35(4), 810-822. 